\title{
Estímulos e barreiras à criatividade na educação a distância'
}

\author{
Incentives and barriers to creativity in \\ the context of distance learning
}

\author{
Thaïs Cardoso SATHLER ${ }^{2}$ \\ Denise de Souza FLEITH ${ }^{3}$
}

\begin{abstract}
Resumo
Este estudo investigou estímulos e barreiras à criatividade na educação a distância. Participaram desta pesquisa 122 alunos de um curso de graduação naquela modalidade. Utilizou-se uma escala que avaliava a percepção dos alunos tanto acerca da implementação, realizada por seu tutor, de práticas pedagógicas que favorecem o desenvolvimento e expressão da criatividade, quanto acerca das barreiras à criatividade na educação a distância. Foram analisados aspectos do projeto político-pedagógico relativos ao desenvolvimento/expressão da criatividade. Os resultados indicaram que práticas pedagógicas que favorecem a criatividade são desenvolvidas pelos tutores. A barreira à criatividade mais citada refere-se à dificuldade de gerenciar o tempo. O projeto político-pedagógico do curso contempla a criatividade e formas de desenvolvê-la na educação a distância. A identificação de estímulos e barreiras à criatividade possibilita que intervenções sejam planejadas e implementadas a fim de catalisar o desenvolvimento/expressão do potencial criativo.
\end{abstract}

Unitermos: Criatividade. Educação a distância. Estudantes universitários. Métodos de ensino.

\begin{abstract}
The purpose of this study was to investigate incentives and barriers to creativity in the context of distance learning. One hundred and twenty-two students of an undergraduate distance course participated in the research. A scale was used to assess the students' perception of both the pedagogical practices which help to develop and express creativity, implemented by their tutors, and the barriers to developing/expressing creativity in distance learning. Aspects of the political and pedagogical design relating to the development/expression of creativity were analyzed. The results showed that the students consider that pedagogical practices implemented by their tutors have developed their creative skills. The barrier to creativity most frequently referred to by the students was the difficulty with time management. The political and pedagogical design of the course includes creativity and ways of fostering it in distanceeducation. The identification of practices that stimulate creativity, as well as the barriers, allows interventions to be planned and implemented in order to enhance the development of students' creative potential.
\end{abstract}

Uniterms: Creativity. Distance education. College students. Teaching methods.

$\boldsymbol{\nabla \nabla \nabla \nabla}$

1 Artigo elaborado a partir da dissertação de T.C. SATHLER, intitulada "Desenvolvimento da criatividade na educação a distância segundo a percepção de universitários". Universidade de Brasília, 2007.

2 Instituto de Pesquisa Econômica Aplicada. Coordenação Geral de Gestão de Pessoas, Diretoria de Desenvolvimento Institucional. SBS, Qda 1, BI. J-BNDES, 70076-900, Brasília, DF, Brasil. Correspondência para/Correspondence to: T.C. SATHLER. E-mail: <thaiscsr@gmail.com>.

3 Universidade de Brasília, Instituto de Psicologia, Programa de Pós-Graduação em Processos de Desenvolvimento Humano e Saúde. Brasília, DF, Brasil. 
Neste século, a habilidade de solucionar problemas e o pensamento crítico e criativo podem ser considerados as ferramentas básicas para lidar com desafios cada vez mais complexos (Alencar, 1996; Starko, 1995). A reprodução de conhecimentos e estratégias adquiridas parece não ser mais suficiente para solucionar os problemas emergentes. Pesquisadores das mais diversas áreas começaram a perceber que, para lidar com as rápidas transformações que estavam ocorrendo no mundo, era necessário estabelecer condições favoráveis à emergência e expressão das habilidades criativas, de modo a se alcançarem respostas originais e mais adequadas aos desafios impostos (Fleith, 1994).

Nesse sentido, é necessário repensar a educação, não apenas em termos do conteúdo a ser trabalhado, mas também no que concerne aos traços de personalidade a serem reforçados e cultivados. Sabe-se hoje que não basta o conhecimento. É preciso também reformular a imagem do aluno ideal, cuja obediência, passividade e conformismo devem dar lugar à coragem, à dedicação, ao entusiasmo, à iniciativa, à autoconfiança - traços que contribuem para a busca de novas perguntas, respostas e soluções (Alencar, 2001). Ou seja, é essencial preparar o aluno para se tornar um aprendiz mais autônomo.

Nesse contexto, a Educação a Distância (EaD) aparece, cada vez mais, como uma forma de educação extremamente adequada e desejável para atender às novas demandas educacionais decorrentes das mudanças na nova ordem econômica mundial (Belloni, 2003). Para Moran (2002), educação a distância é o processo de ensino-aprendizagem, mediado por tecnologias, em que professores e alunos estão separados espacial e/ou temporalmente. Assim, na atualidade, entende-se que a característica mais importante da EaD é sua flexibilidade temporal e espacial, que possibilita implementar propostas educacionais organizadas e adequadas à realidade em que vivem muitas pessoas que desejam continuar estudando (Coiçaud, 2001).

Outros autores ressaltam, ainda, em suas definições, aspectos diversos que consideram essenciais. Almeida (2003), por exemplo, enfatiza a administração do tempo pelo aluno e o desenvolvimento da autonomia ao realizar as atividades. Sousa (2004) chama atenção para a possibilidade concreta de democratizar o saber, tornando possível o sonho e desejo de educação para todos. Castro et al. (2005), por outro lado, destacam aspectos relativos à comunicação dentro do processo, como meios e estratégias.

Assim, o ator principal no palco da educação a distância é o aluno. Tal fato exige o desenvolvimento de determinadas capacidades e habilidades essenciais para o processo de ensino-aprendizagem. $\mathrm{O}$ aluno deve estar motivado para aprender, ter perseverança e responsabilidade, ter hábito de planejamento e visão de futuro, ser pró-ativo, comprometido e autodisciplinado (Castro et al., 2005). Além disso, é importante adquirir a capacidade de não depender do juízo de outros, ter clareza sobre as próprias necessidades de estudo, tomar iniciativas próprias e refletir sobre a própria aprendizagem (Peters, 2003).

Para isso, o aluno deve ser incentivado a estudar e pesquisar de modo independente e colaborativo. A comunicação e a troca de informação entre os alunos devem ser intensificadas de modo a consolidar a aprendizagem por meio de atividades individuais ou grupais (Castro et al., 2005). Um estudo autorregulado pode desdobrar-se somente se os estudantes puderem agir em um ambiente em que haja apoio, incentivo e compreensão. O aluno deixa de ser aquele a quem se ensina, e passa a ser um sujeito que aprende a aprender.

O tutor, figura também importante para construção desse conhecimento, atua nos seguintes papéis: (a) assessor pedagógico, na função de orientação e solução de dúvidas em relação aos conteúdos; (b) orientador de aprendizagem, provocando a reflexão e o intercâmbio de experiências; (c) incentivador do trabalho colaborativo; (d) facilitador da interação do aluno com as fontes de informação; (e) fomentador da comunicação interpessoal entre os participantes do processo; e ( $f$ ) motivador para o resultado (Castro \& Ferreira, 2006).

Dessa forma, o tutor, apoiado em diferentes ferramentas pedagógicas, irá propiciar a interação do aprendiz com os diversos objetos de estudo/conhecimento, colocando-o como sujeito participativo da sua aprendizagem. Assim, o tutor deve atuar como um facilitador, em uma atitude de coautor no processo de construção/produção do conhecimento, apontando possibilidades de novos caminhos (Almeida, 2003; Belloni, 2003; Castro et al., 2005).

A área de pesquisa em EaD abrange diversos temas. Williams, Nicholas e Gunter (2005), realizando 
uma revisão de temas estudados na área, relatam que a pesquisa em EaD busca, principalmente, confirmar a efetividade dessa forma de ensino, bem como maneiras de mantê-la e aumentá-la. Há opiniões divergentes sobre a efetividade da EaD, mas essa discussão, apesar de relevante, foge ao escopo deste trabalho.

Vianna e Alencar (2006) chamaram a atenção para o fato de que o tema criatividade em cursos a distância tem sido pouco explorado nas pesquisas da área. Assim, desenvolveram um estudo, no contexto brasileiro, a respeito da criatividade em $\mathrm{EaD}$, que teve como objetivo investigar a percepção de tutores acerca da promoção do potencial criativo dos alunos no curso em que estavam envolvidos, bem como barreiras ao desenvolvimento e expressão do potencial criativo dos alunos em ambientes educacionais online. Os resultados mostraram que $73,08 \%$ dos tutores acreditam que o curso com o qual estão envolvidos promove o desenvolvimento e a expressão do potencial criativo dos alunos. As justificativas apresentadas pelos tutores envolvem a boa qualidade de interação entre aluno e tutor, o estímulo por parte deste a trabalhos criativos e colaborativos, e a implementação de diversas práticas pedagógicas que favorecem a expressão criativa dos estudantes em ambientes virtuais. Os tutores apontaram como principais barreiras ao desenvolvimento e expressão do potencial criativo: dificuldades dos alunos em participar de cursos online, falta de interesse dos alunos nos assuntos do curso, dificuldades dos estudantes em ambientes virtuais e pouca participação dos mesmos.

Educadores e psicólogos cada vez mais têm enfatizado a importância de se promoverem condições favoráveis ao desenvolvimento do potencial criativo dos alunos por diversas razões. Uma delas é o fato de as experiências criativas de aprendizagem serem uma das vias para o bem-estar emocional, pois são acompanhadas de sentimentos de satisfação e prazer. Também ressaltada é a capacidade de pensar de forma criativa e inovadora, aliada à apresentação de traços de personalidade que se associam à criatividade, ajudando o futuro profissional a lidar com os desafios e complexidade típicos deste milênio (Alencar \& Fleith, 2003a). Como consequência, vários estudos com foco nos estímulos e barreiras à criatividade no contexto educacional passaram a ser desenvolvidos.

Alencar (1997; 2002), por exemplo, analisou a extensão em que a criatividade vem sendo estimulada no contexto universitário (graduação e pós-graduação). Os resultados indicaram que os graduandos consideram que há pouco incentivo a distintos aspectos da criatividade por parte dos docentes. Observou-se que, de modo geral, percebiam os seus professores como pouco ou muito pouco criativos. Possivelmente, segundo a autora, essa percepção reflete o comportamento do professor que em sala de aula pouco estimula a criatividade. Tal resultado sugere a ênfase limitada que se dá à criatividade por parte dos professores universitários, que estariam mais preocupados com seu papel de transmissores de informação. No entanto, constatou-se que os pós-graduandos consideram que seus professores, se comparados aos dos graduandos, oferecem maior incentivo a distintos aspectos que favorecem a expressão da criatividade.

Também T.V. Santeiro, F. R. M. Santeiro e Andrade (2004) desenvolveram uma pesquisa a respeito da percepção de universitários com relação a professores facilitadores e inibidores da criatividade. Os resultados mostraram que as características apontadas como próprias dos professores facilitadores ou inibidores do desenvolvimento das habilidades criativas enquadram-se em aspectos relacionados ao preparo do docente e ao modo como ele se relaciona com os alunos. São os dois lados de uma mesma moeda. A preparação do professor e o relacionamento entre ele e aluno tanto podem servir para desenvolver o potencial criativo, como para miná-lo. A respeito de outros aspectos que inibem a criatividade, diversos estudos no contexto educacional apontam a falta de tempo e oportunidade como um dos principais fatores que dificultam o desenvolvimento e a expressão da criatividade pessoal (Alencar \& Fleith, 2003b; Alencar, Fleith \& Martínez, 2003; Joly \& Guerra, 2004; Ribeiro \& Fleith, 2007).

Oliveira (2010) destaca o contexto educacional como um dos fatores influentes no desenvolvimento do potencial criativo, segundo as teorias sistêmicas da criatividade, e aponta a necessidade de mais pesquisas sobre o assunto. As pesquisas encontradas a respeito de criatividade em educação referem-se, em sua grande maioria, ao ensino presencial. Foi encontrado apenas um estudo sobre criatividade em EaD, tema que, embora novo, é de extrema relevância para o cenário educacional atual. Muito embora o contexto educacional formal esteja presente no dia a dia das pessoas desde a 
infância, a importância e impacto da educação para adultos tem aumentado nos últimos anos, pois há cada vez mais a necessidade de atualização e desenvolvimento de habilidades cognitivas para o desempenho profissional.

Assim, dada a crescente importância tanto da utilização da criatividade quanto do fortalecimento da educação a distância como modalidade de ensino, o objetivo do presente estudo foi investigar estímulos e barreiras à criatividade na educação a distância. Para alcançar tal objetivo foram analisados: (a) a percepção de estudantes universitários a respeito de elementos que favorecem ou inibem a criatividade no contexto da EaD, e (b) aspectos do projeto político-pedagógico do curso investigado, relativos ao desenvolvimento/expressão da criatividade.

\section{Método}

\section{Participantes}

Participaram desta pesquisa 122 alunos de um curso de graduação em Administração a distância, oferecido por uma universidade situada na região centro-oeste do país. Dada a dificuldade de seleção randômica e o caráter voluntário de participação, optou-se pela utilização de uma amostra de conveniência (M. D. Gall, Borg \& J. P. Gall, 1996).

A idade média dos alunos era de 32,75 anos, variando entre 17 e 56 anos. Do total de participantes, 87 eram do sexo masculino $(71,3 \%$ ) e 35 do sexo feminino (28,7\%). Quase todos os participantes informaram que trabalhavam ( $n=112)$, sendo que $83 \%$ tinham uma jornada semanal de 40 horas de trabalho. A maioria dos participantes $(n=108)$ residia no Distrito Federal.

O curso de graduação do qual os participantes deste estudo fazem parte é um projeto-piloto que tem como objetivo ofertar gratuitamente à sociedade um curso de qualidade com a conveniência do estudo a distância, desenvolvido em uma perspectiva centrada no aluno. Está previsto que o curso tenha uma duração de quatro anos e meio, com carga horária total de três mil horas/aula. A estrutura curricular adotada é a modular. Cada módulo conta com os seguintes recursos didáticos: livro impresso, encontros presenciais para realização de avaliação e apresentação de trabalhos, ambiente virtual de aprendizagem e tutoria a distância.

A proposta do curso é que o universitário seja apoiado por um sistema de tutoria que permita o monitoramento direto do desempenho e do fluxo de atividades, facilitando a interatividade e identificação de possíveis dificuldades de aprendizagem. Cada tutor acompanha 25 alunos. A comunicação e a divulgação de informações são realizadas por meio da internet, do telefone, do correio postal e do fax. No ambiente virtual de aprendizagem, os tutores podem interagir com seus alunos por meio das ferramentas do mural, biblioteca, fórum e chat.

\section{Instrumentos}

Para avaliar a percepção dos estudantes acerca dos elementos favorecedores e inibidores do desenvolvimento e da expressão da criatividade no contexto de educação a distância, foi utilizado um questionário elaborado para o presente estudo, composto por duas partes. A primeira parte incluiu uma versão adaptada ao contexto de educação a distância, com a devida autorização das autoras, do instrumento denominado "Inventário de Práticas Docentes que Favorecem a Criatividade no Ensino Superior", construído e validado por Alencar e Fleith (2004). Esse instrumento permite avaliar a percepção de estudantes universitários quanto à extensão em que seus professores apresentam comportamentos e implementam práticas docentes que favorecem o desenvolvimento e expressão da criatividade do aluno. Os itens foram respondidos em uma escala de 5 pontos, que varia de "discordo plenamente" até "concordo plenamente". A segunda parte do instrumento foi composta por um check list de barreiras ao desenvolvimento/expressão da criatividade pessoal no contexto de EaD, segundo a percepção dos alunos. A elaboração deste check list foi inspirada no instrumento utilizado por Vianna (2005).

Complementou o instrumento uma página inicial, composta por questões relativas a dados biográficos, destinada à identificação dos participantes. Um estudo-piloto foi realizado a fim de verificar a clareza dos itens e das instruções, bem como analisar semanticamente os itens do instrumento. Para tal, solicitou-se, via e-mail, a dezalunos do curso estudado a avaliação dos aspectos 
citados anteriormente. Quatro estudantes enviaram seus comentários. Na parte relativa a barreiras ao desenvolvimento/expressão da criatividade, o termo "assincronicidade", utilizado na versão inicial, gerou dúvidas. A partir das sugestões desses estudantes, o item foi reformulado a fim de garantir a clareza da linguagem. Assim, a redação final dessa barreira foi: "Comunicação Assíncrona (diálogo não ocorre em tempo real)".

\section{Procedimentos}

Após verificação junto à coordenadora pedagógica a respeito da viabilidade de realização do presente estudo e contato formal com o diretor da instituição, foi obtida a autorização para o início da pesquisa. A partir desse momento, foram realizados contatos com os responsáveis diretos pelo curso pesquisado, com vistas a proceder aos ajustes necessários para que a coleta de dados se iniciasse e para a aplicação do estudo-piloto e discussão sobre a melhor forma de disponibilizar o instrumento para os alunos. A alternativa encontrada junto ao coordenador do curso foi aplicar o instrumento via Internet. Assim, foi desenvolvido um site específico para a coleta de dados. Uma mensagem aos alunos, juntamente com o link para este site, foi inserida no ambiente virtual de aprendizagem do curso.

Assim que o participante acessava o link, a página inicial da pesquisa apresentava os objetivos do estudo e o termo de consentimento livre e esclarecido. Caso o estudante não desejasse participar, bastava clicar na opção "não aceito participar", sendo então encaminhado para uma página de agradecimento. Entretanto, se o aluno desejasse participar, ao clicar na opção "aceito participar", era encaminhado para a página de identificação. O preenchimento de todos os campos dessa página, exceto o campo destinado ao e-mail, era obrigatório. Após preencher a parte de identificação, ao clicar em "continuar", o participante era encaminhado para o questionário. Na primeira parte - questionário de práticas pedagógicas - o preenchimento de todos os campos também era obrigatório. Na segunda parte - check list de barreiras - era solicitado ao participante marcar apenas os itens que ele considerasse barreiras ao desenvolvimento/expressão de sua criatividade no contexto de EaD. Ao final do questionário o participante clicava em concluir e era encaminhado para uma página de agradecimento.
Todos os princípios éticos foram cumpridos. Foram assegurados a todos os participantes no termo de consentimento livre e esclarecido: (a) explicação sobre os objetivos do trabalho, (b) possibilidade de deixar a pesquisa a qualquer momento que desejassem, (c) confidencialidade dos dados, (d) acesso ao telefone e endereço eletrônico de contato de uma das pesquisadoras, para esclarecimento de dúvidas sobre o projeto.

Para análise de dados foi utilizado o Programa Statistic Package for Social Science (SPSS) para efetuar a análise dos dados do questionário. Foram utilizados procedimentos estatísticos descritivos (média e frequência).

Utilizou-se a análise de conteúdo para o exame documental dos aspectos do projeto político-pedagógico relacionados ao desenvolvimento/expressão e inibição da criatividade no curso a distância examinado neste estudo. Unidades de registro (temas - asserções sobre determinado assunto) foram utilizadas como unidades de análise do projeto político-pedagógico, tendo elas sido agrupadas, gerando categorias. A frequência de cada tema foi utilizada como indicador de importância (Franco, 2005).

\section{Resultados}

Na Tabela 1, são apresentados a média e desvio-padrão de cada item da primeira parte do questionário. Os itens que apresentaram as maiores médias foram: está disposto a elucidar dúvidas dos alunos, cria um ambiente de respeito e aceitação pelas ideias dos alunos, e tem entusiasmo pelo módulo sob sua responsabilidade. Por outro lado, as médias mais baixas foram observadas nos seguintes itens: preocupa-se apenas com o conteúdo informativo e utiliza critérios de avaliação que exigem do aluno apenas a reprodução do conteúdo contido no material didático.

Na Tabela 2, são apresentados a frequência e o percentual de cada barreira, sendo as mais mencionadas: dificuldade de gerenciar o tempo, poucas oportunidades para discutir e trocar ideias com colegas, e comunicação assíncrona. Por outro lado, as barreiras menos citadas foram: dificuldade de aprendizagem em ambientes virtuais, insegurança para navegar em ambientes virtuais, dificuldade em participar de cursos em educação a distância, e falta de autonomia. 
Tabela 1. Média (M) e Desvio-Padrão (DP) dos itens relativos às práticas pedagógicas.

\begin{tabular}{|c|c|c|}
\hline Em sua opinião, o seu tutor: & M & DP \\
\hline Está disposto a elucidar dúvidas dos alunos & 4,37 & 0,69 \\
\hline Cria um ambiente de respeito e aceitação pelas ideias dos alunos & 4,30 & 0,66 \\
\hline Tem entusiasmo pelo módulo sob sua responsabilidade & 4,28 & 0,68 \\
\hline Tem expectativas positivas com relação ao desempenho dos alunos & 4,23 & 0,67 \\
\hline Cultiva nos alunos o gosto pela descoberta e pela busca de novos conhecimentos & 4,21 & 0,69 \\
\hline Desenvolve a autonomia do aluno & 4,17 & 0,67 \\
\hline Desperta o interesse dos alunos pelo conteúdo abordado & 4,16 & 0,73 \\
\hline Promove o debate com estímulo a participação de todos os alunos & 4,12 & 0,81 \\
\hline Está atento aos interesses dos alunos & 4,12 & 0,76 \\
\hline Incentiva a independência dos alunos & 4,11 & 0,80 \\
\hline Incentiva os alunos a fazerem questões relativas aos temas estudados & 4,06 & 0,89 \\
\hline Valoriza as ideias originais dos alunos & 4,03 & 0,85 \\
\hline Faz perguntas, buscando conexões com assuntos abordados & 4,03 & 0,82 \\
\hline Estimula os alunos a analisarem diferentes aspectos de um problema & 4,02 & 0,83 \\
\hline Estimula a iniciativa dos alunos & 4,02 & 0,84 \\
\hline Dá chances aos alunos para discordarem de seus pontos de vistas & 4,02 & 0,79 \\
\hline Desenvolve nos alunos habilidades de análise crítica & 4,01 & 0,83 \\
\hline Dá feedback construtivo aos alunos & 4,00 & 0,91 \\
\hline Oferece informações adicionais importantes e interessantes relativas ao conteúdo do módulo & 3,99 & 0,83 \\
\hline Estimula o aluno a pensar ideias novas relacionadas ao conteúdo do módulo & 3,98 & 0,86 \\
\hline Leva o aluno a perceber e conhecer pontos de vistas divergentes sobre o mesmo problema ou tema de estudo & 3,96 & 0,81 \\
\hline Estimula a curiosidade dos alunos & 3,93 & 0,81 \\
\hline Tem senso de humor & 3,93 & 0,88 \\
\hline Faz perguntas desafiadoras que motivam os alunos a pensar e raciocinar & 3,91 & 0,82 \\
\hline Utiliza exemplos para ilustrar o que está sendo abordado no módulo & 3,90 & 0,93 \\
\hline Promove a autoconfiança dos alunos & 3,89 & 0,80 \\
\hline Apresenta vários aspectos de uma questão que está sendo estudada & 3,83 & 0,89 \\
\hline Tem disponibilidade para atender os alunos fora do horário de plantão & 3,75 & 0,89 \\
\hline Apresenta situações-problema a serem solucionadas pelos alunos & 3,62 & 0,96 \\
\hline Preocupa-se apenas com o conteúdo informativo & 3,49 & 1,00 \\
\hline Utiliza critérios de avaliação que exigem do aluno apenas a reprodução do conteúdo contido no material didático & 3,38 & 1,24 \\
\hline
\end{tabular}

Tabela 2. Frequência e percentual das barreiras ao desenvolvimento/expressão da criatividade percebidas pelos alunos.

\begin{tabular}{lcc}
\hline Barreiras & $f$ & $\%$ \\
\hline Dificuldade de gerenciar o tempo & 60 & 49,2 \\
Poucas oportunidades para discutir e trocar ideias com colegas & 50 & 41,0 \\
Comunicação assíncrona & 40 & 32,8 \\
Poucas oportunidades para discutir e trocar ideias com tutor & 38 & 31,1 \\
Desinteresse pelo conteúdo abordado & 30 & 24,6 \\
Falta de entusiasmo pela atividade proposta & 28 & 23,0 \\
Baixo incentivo para inovar & 20 & 16,4 \\
Falta de domínio das ferramentas da web & 17 \\
Falta de incentivo do tutor & 16,9 \\
Qualidade do material pedagógico & 16 \\
Falta de apoio tutorial na implementação de projetos inovadores & 13,1 \\
Dificuldade de aprendizagem em ambientes virtuais & 13,1 \\
Insegurança para navegar em ambientes virtuais & 13 & 12,3 \\
Dificuldade em participar de cursos em educação a distância & 12 & 10,7 \\
Falta de autonomia & 9,8 & 9 \\
\hline
\end{tabular}


Na análise de conteúdo do projeto político-pedagógico do curso, foram encontrados apenas temas relacionados a fatores favorecedores da criatividade no contexto educacional. Tais temas foram agrupados em quatro categorias: Tecnologia Instrucional Facilitadora da Criatividade ( $f=70 ; 52,2 \%$ ), Desenvolvimento de Características Individuais Associadas à Criatividade ( $f=31$; $23,1 \%)$, Conhecimento $(f=27 ; 20,1 \%)$ e Educadores $(f=6$; $4,5 \%)$. O anexo apresenta os temas que compõem cada categoria e alguns exemplos ilustrativos.

\section{Discussão}

Os itens que obtiveram as médias mais elevadas contemplam uma das dimensões do modelo de aprendizagem criativa proposto por Renzulli (1992), o educador. Segundo o autor, o papel do educador em quase todas as situações formais de ensino-aprendizagem é bem valorizado e pode ser de fato o ingrediente mais importante. Nesse sentido, as características destacadas por ele são: conhecimento da disciplina, utilização de técnicas instrucionais que promovam o desenvolvimento da criatividade, e romance com a disciplina. $\mathrm{Ou}$ seja, para que o tutor implemente as práticas mencionadas, assim como outras favorecedoras da criatividade na EaD, é importante que ele apresente ou desenvolva essas características.

As práticas" preocupa-se apenas com o conteúdo informativo"e "utiliza critérios de avaliação que exigem do aluno apenas a reprodução do conteúdo contido no material didático" não são adequadas ao desenvolvimento/expressão da criatividade. O fato de terem obtido as menores médias indica que, segundo a percepção dos alunos, seus tutores pouco as utilizam. Esse resultado diverge da percepção dos tutores a respeito das mesmas práticas no estudo de Vianna (2005), os quais consideram que tais práticas estariam sendo utilizadas. Provavelmente, a formação didática dos tutores que atuaram no curso estudado é diferente da formação dos tutores que participaram do estudo realizado por Vianna. Os resultados obtidos indicam que os tutores avaliados preocupam-se com a construção do conhecimento, e não com a mera reprodução.

Com relação aos fatores inibidores da criatividade, observou-se que a barreira mais apontada pelos alunos foi a "dificuldade de gerenciar o tempo". Esta se refere a aspectos internos ao indivíduo. O perfil do aluno a distância difere daquele do aluno presencial, exigindo maior disciplina e organização no que concerne ao tempo. Contudo, gerenciar o tempo é uma habilidade pouco desenvolvida em nossa cultura. A questão do tempo na produção criativa já foi investigada anteriormente, e os resultados indicam um destaque para fatores relacionados à falta de tempo e de oportunidade entre as barreiras pessoais à criatividade mais mencionadas por professores e alunos, especialmente no ensino superior (Alencar \& Fleith, 2003b; Alencar et al., 2003; Joly \& Guerra, 2004; Ribeiro \& Fleith, 2007).

Estratégias para lidar com a dificuldade de gerenciar o tempo devem ser desenvolvidas, como, por exemplo, ajudar os alunos a estabelecer prioridades e organizar suas atividades diárias de acordo com sua real importância e relevância. Os tutores e a coordenação do curso podem levantar a discussão para que os alunos reflitam sobre como estão alocando suas atividades diárias de acordo com o tempo disponível. É importante que os alunos percebam que administrar o tempo é ganhar autonomia sobre as prioridades individuais, e não viver em função de horários.

Outras barreiras destacadas foram "poucas oportunidades para discutir e trocar ideias com colegas" e "comunicação assíncrona". Ambas se referem a fatores externos ao indivíduo. Apesar do desenvolvimento de diversas tecnologias de informação e comunicação, os alunos podem ainda não ter se adaptado a esse tipo de ferramenta. Provavelmente, essas barreiras serão percebidas de forma diferente quando se vislumbrarem vantagens em outras formas de discussão e houver a valorização destas.

Kristensson e Norlander (2003) investigaram os efeitos da tecnologia da informação no processo e desempenho criativo de grupos de universitários em três situações - salas de conversação na Internet, videoconferência e face a face - e constataram que grupos presenciais obtiveram mais resultados criativos e maior satisfação com seu processo e produção em comparação a grupos cuja comunicação foi estabelecida via chat. Contudo, os autores sugerem que, se fosse disponibilizado tempo suficiente para o término da tarefa nos grupos que utilizaram o chat, talvez a produção pudesse ser aproximadamente a mesma dos grupos presenciais. Ou seja, não basta apenas utilizar os recursos tecnológicos, é preciso saber utilizá-los da melhor forma possível, para que eles possam ser otimizados. 
Francescato, Mebane, Porcelli, Attanasio e Pulino (2007) compararam a eficácia da aprendizagem colaborativa em cursos presenciais e a distância e concluíram que o nível de discussão em grupo dos alunos a distância, realizada em fóruns, foi superior. Os autores atribuem este resultado ao fato da assincronicidade permitir o surgimento de um número maior de pontos de vistas diversos, pois não há interrupções e os participantes podem elaborar melhor suas ideias antes de comunicá-las ao grupo.

Esses resultados indicam que o tutor pode utilizar práticas pedagógicas que permitam uma interação de melhor qualidade, como, por exemplo, criar um fórum de discussão semanal com temáticas pertinentes não só ao conteúdo do curso, como também relativas ao processo de ensino-aprendizagem em educação a distância. Essa troca de experiências pode levar o aluno a descobrir outros aspectos que não havia pensado antes, bem como a observar sob outro ponto de vista. O tutor pode também disponibilizar um horário em que estará disponível diariamente no chat. Dessa forma, os alunos podem se programar para entrar em contato com ele e diminuir um pouco o impacto percebido como negativo da comunicação assíncrona. É importante que os tutores fiquem atentos ao tempo de retorno aos e-mails e mensagens dos alunos, pois esse fator afeta a percepção deles a respeito da comunicação assíncrona. Se o tempo de resposta do tutor for reduzido, o desejo do aluno de uma comunicação imediata pode ser atenuado. É interessante que o tutor, no mínimo, sinalize que recebeu e leu o e-mail do aluno, mesmo que não solucione de imediato o que foi solicitado, pois é essencial que ele mantenha ativo esse vínculo.

Já com relação às barreiras menos selecionadas pelos alunos, nota-se que estão associadas somente a fatores que thes são internos: "dificuldade de aprendizagem em ambientes virtuais", "insegurança para navegar em ambientes virtuais", "dificuldade em participar de cursos em educação a distância" e "falta de autonomia". Esse resultado pode estar vinculado ao fato de que a grande maioria dos participantes trabalha. Sabe-se que o mercado de trabalho hoje está quase completamente informatizado, ou seja, para grande parte dos participantes não deve haver vivências relacionadas à exclusão digital. Muitas organizações públicas e privadas utilizam a EaD na educação continuada de seus trabalhadores, de modo que ela já faz parte do cotidiano desses 464 alunos.
A análise do projeto político-pedagógico indicou que ele propõe formas de implementar o desenvolvimento da criatividade na educação a distância. Chama atenção o grande investimento, proposto para o curso, em tecnologia instrucional facilitadora da criatividade. Esse resultado ilustra a previsão de Peters (2003) de que, devido à grande quantidade de novas possibilidades do design didático, aumenta a viabilidade de uma estruturação bem mais variável e flexível do que tem sido oferecido até agora no ensino a distância. Por outro lado, aspectos relativos aos educadores foram menos mencionados. Contudo, não se pode deixar de lado a capacitação desses profissionais, pois, conforme Belloni (2003) lembra, a formação inicial de professores tem que prepará-los para lidar com a inovação tecnológica e dela lançar mão na sua prática. É necessário também prepará-los para a formação continuada, numa perspectiva de capacitação ao longo da vida. Além disso, os novos desafios do ensino perpassam pelo desenvolvimento de um trabalho pedagógico criativo, gerando ações inovadoras no processo de ensino-aprendizagem. Pensar num trabalho pedagógico inovador envolve a motivação e pressupõe que o professor tenha uma didática interessante, instigante e inteligente - enfim, criativa (Barreto \& Martínez, 2007).

Uma limitação do presente estudo refere-se ao tipo de amostra. O grau de generalização é baixo, pois foi utilizada uma amostra de conveniência. O presente estudo não examinou outros fatores que podem estimular ou inibir a criatividade na EaD, como, por exemplo, material didático, ambiente virtual de aprendizagem, percepção dos tutores e características individuais dos alunos. É necessário, pois, que esses e outros aspectos sejam estudados para que se construa um campo de conhecimento sólido a respeito da criatividade na EaD. Afinal, sabe-se que cada contexto educacional apresenta suas especificidades, por se tratar de uma construção realizada pela interação de educadores, alunos, ambiente físico e social e recursos disponíveis, entre outros fatores.

A identificação de práticas favorecedoras da criatividade, bem como de barreiras, possibilita que intervenções sejam planejadas e executadas a fim de catalisar o desenvolvimento/expressão do potencial dos alunos, como, por exemplo, a capacitação de tutores objetivando instrumentalizá-los para um processo de ensino-aprendizagem criativo. Com base nos resultados obtidos no presente estudo, algumas sugestões podem 
ser dadas para pesquisas futuras: (a) investigar barreiras à criatividade pessoal dos tutores na EaD, (b) examinar outros fatores favorecedores e inibidores da criatividade na EaD vinculados ao ambiente virtual de aprendizagem, interação com os colegas, perfil dos alunos e material didático e (c) examinar a atuação do tutor e da equipe pedagógica responsável no que toca à observância dos pressupostos do projeto político-pedagógico, a fim de verificar sua influência sobre o desenvolvimento do potencial criativo dos alunos.

\section{Referências}

Alencar, E. M. L. (1996). A gerência da criatividade. São Paulo: Makron

Alencar, E. M. L. S. (1997). O estímulo à criatividade no contexto universitário. Psicologia Escolar e Educacional, 1 (2-3), 29-37.

Alencar, E. M. L. S. (2001). Criatividade e educação de superdotados. Petrópolis: Vozes.

Alencar, E. M. L. (2002). O estímulo à criatividade em programas de pós-graduação segundo seus estudantes. Psicologia: Reflexão e Crítica, 15 (1), 63-70.

Alencar, E. M. L. S., \& Fleith, D. S. (2003a). Criatividade: múltiplas perspectivas. Brasília: EdUnB.

Alencar, E. M. L. S., \& Fleith, D. S. (2003b). Barreiras à criatividade pessoal entre professores de distintos níveis de ensino. Psicologia: Reflexão e Crítica, 16 (1), 63-69.

Alencar, E. M. L. S., \& Fleith, D. S. (2004). Inventário de práticas docentes que favorecem a criatividade no ensino superior. Psicologia: Reflexão e Crítica, 17 (1), 105-110.

Alencar, E. M. L. S., Fleith, D. S., \& Martínez, A. M. (2003). Obstacles to personal creativity between Brazilian and Mexican university students: a comparative study. Journal of Creative Behavior, 37 (3), 179-192.

Almeida, M. E. B. (2003). Educação a distância na internet: abordagens e contribuições dos ambientes digitais de aprendizagem. Educação e Pesquisa, 29 (2), 327-340.

Barreto, M. O., \& Martínez, A. M. (2007). Possibilidades criativas de profesores em cursos de pós-graduação stricto sensu. Estudos de Psicologia (Campinas), 24 (4), 463-473.

Belloni, M. L. (2003). Educação a distância. São Paulo: Autores Associados.

Castro, M. N. M., \& Ferreira, L. D. V. (2006). TD\&E a distância: múltiplas mídias e clientelas. In J. E. Borges-Andrade, G. S. Abbad \& L. Mourão (Orgs.), Treinamento, desenvo/vimento e educação em organizações e trabalho (pp.322-339). Porto Alegre: Artmed.

Castro, N. J., Haguenauer, C., Silva, E. M., Alves, L. A., Washington, M. G. M., Carvalho, M. B., et al. (2005). O estudo a distância com apoio da internet. Recuperado em junho 25, 2005, disponível em: http://www.abed.org.br/ publique/cgi/cgilua.exe/sys/start.htm?UserActive Template $=4$ abed\&infoid $=137 \&$ sid $=116$
Coiçaud, S. (2001). A colaboração institucional na educação a distância. In I.E. Litwin (Org.), Educação a distância: temas para o debate de uma nova agenda educativa (pp.5372). São Paulo: Artmed.

Fleith, D. S. (1994). Treinamento e estimulação da criatividade no contexto educacional. In E. M. L. Alencar \& A. M. R. Virgolim (Orgs.), Criatividade: expressão e desenvolvimento (pp.113-141). Petrópolis: Vozes.

Francescato, D., Mebane, M., Porcelli, R., Attanasio, C., \& Pulino, M. (2007). Developing professional skills and social capital through computer supported collaborative learning in university contexts. International Journal of Human-Computer Studies, 65 (2), 140-152.

Franco, M. L. P. B. (2005). Análise do conteúdo. Brasília: Liber Livro.

Gall, M. D., Borg, W. R., \& Gall, J. P. (1996). Educational research $\left(6^{\text {th }}\right.$ ed.). White Plains, NY: Longman.

Joly, M. C. R. A., \& Guerra, P. B. C. (2004). Compreensão em leitura e barreiras à criatividade: um estudo com universitários ingressantes. Psico, 35 (2), 151-159.

Kristensson, P., \& Norlander, T. (2003). The creative product and process in computer-mediated groups. The Journal of Creative Behavior, 37 (4), 223-243.

Moran, J. M. (2002). O que é educação a distância. Recuperado em fevereiro 4, 2007, disponível em: http://www.eca.usp. br/prof/moran/dist.htm

Oliveira, Z. M. F. (2010). Fatores influentes no desenvolvimento do potencial criativo. Estudos de Psicologia (Campinas), 27 (1), 83-92. doi: 10.1590/S0103-166X2010000 100010.

Peters, O. (2003). Didática do ensino a distância. São Leopoldo: Unisinos.

Renzulli, J. S. (1992). A general theory for the development of creative productivity through the pursuit of ideal acts of learning. Gifted Child Quarterly, 36 (4), 170-182.

Ribeiro, R. A., \& Fleith, D. S. (2007). O estímulo à criatividade em cursos de licenciatura. Paidéia, 17 (38), 403-416.

Santeiro, T. V., Santeiro, F. R. M., \& Andrade, I. R. (2004). Professor facilitador e inibidor da criatividade segundo universitários. Psicologia em Estudo, 9 (1), 95-102.

Sousa, M. F. G. (2004). Aprender a aprender em educação a distância: a construção da autonomia do aprendiz. São Paulo: Moderna.

Starko, A. J. (1995). Creativity in the classroom. White Plains, NY: Longman

Vianna, C. R. G. V. (2005). Expressão e desenvolvimento da criatividade em ambientes de ensino-aprendizagem on-line. Dissertação de mestrado não-publicada, Universidade Católica de Brasília.

Vianna, C. R. G. V., \& Alencar, E. M. L. S. (2006). Creativity and barriers to its expression in on-line education courses. Gifted Education International, 21 (1), 54-62.

Williams, P., Nicholas, D., \& Gunter, B. (2005). E-learning: What the literature tells us about distance education. Aslib Proceedings: New Information Perspectives, 57 (2), 109-122.

Recebido em: 5/3/2009

Versão final reapresentada em: 5/8/2010

Aprovado em: 9/9/2010 
ANEXO

FATORES FAVORECEDORES DA CRIATIVIDADE CONTEMPLADOS NO PROJETO POLÍTICO-PEDAGÓGICO.

\begin{tabular}{|c|c|c|}
\hline Categorias & Temas & Exemplo \\
\hline $\begin{array}{l}\text { Tecnologia } \\
\text { Instrucional } \\
\text { Facilitadora da } \\
\text { Criatividade }\end{array}$ & $\begin{array}{l}\text { - Diversificação de técnicas, estratégias } \\
\text { - Utilização de métodos que levem ao } \\
\text { questionamento } \\
\text { - Individualização do processo de } \\
\text { ensino-aprendizagem } \\
\text { - Ênfase na construção do conheci- } \\
\text { mento } \\
\text { - Espaço para divulgação dos trabalhos } \\
\text { dos alunos }\end{array}$ & $\begin{array}{l}\text { "... combinação de materiais didáticos: impressos, } \\
\text { videoaulas, Internet, videoconferências, teleconferências, } \\
\text { e principalmente um sistema de acompanhamento ao } \\
\text { estudante a distância com apoio de tutores e monitores } \\
\text { via 0800, fax, e-mail e correio postal". } \\
\text { "No desenvolvimento do curso serão realizados encon- } \\
\text { tros presenciais e seminários temáticos. Em cada semestre } \\
\text { será proposto um tema de pesquisa relacionado às áreas } \\
\text { estudadas...". } \\
\text { "Por meio do Sistema de Acompanhamento cada estu- } \\
\text { dante receberá retorno individualizado sobre o seu } \\
\text { desempenho, ... bem como orientações e trocas de } \\
\text { informações complementares relativas aos conteúdos } \\
\text { abordados em exercícios desenvolvidos...". }\end{array}$ \\
\hline $\begin{array}{l}\text { Desenvolvimento de Características } \\
\text { Individuais Associadas } \\
\text { à Criatividade }\end{array}$ & $\begin{array}{l}\text { - Habilidades cognitivas } \\
\text { - Aspectos motivacionais } \\
\text { - Traços personológicos }\end{array}$ & $\begin{array}{l}\text { "... estimular o desenvolvimento do pensamento } \\
\text { autônomo, da curiosidade e criatividade". } \\
\text { "... estimular o aluno em momentos de dificuldades para } \\
\text { que não desista do curso; ...". }\end{array}$ \\
\hline Conhecimento & $\begin{array}{l}\text { - Domínio do conhecimento factual } \\
\text { - Interdisciplinaridade e multidisciplina- } \\
\text { ridade } \\
\text { - Incentivo a busca de informação } \\
\text { adicional }\end{array}$ & $\begin{array}{l}\text { "... Nortear a concepção, criação e produção dos materiais } \\
\text { didáticos, de forma a que contemplem e integrem os } \\
\text { tipos de saberes hoje reconhecidos como essenciais às } \\
\text { sociedades do Século XXI: os fundamentos teóricos e } \\
\text { princípios básicos dos campos de conhecimento; as } \\
\text { técnicas, práticas ...". } \\
\text { "Adotar um enfoque pluralista no tratamento dos temas } \\
\text { e conteúdos, recusando posicionamentos unilaterais, } \\
\text { normativos ou doutrinários". } \\
\text { "... estimular o aluno a ampliar seu processo de leitura, } \\
\text { extrapolando o material didático ....". }\end{array}$ \\
\hline Educadores & $\begin{array}{l}\text { - Formação acadêmica adequada à } \\
\text { função exercida } \\
\text { - Capacitação para atuar em EAD }\end{array}$ & $\begin{array}{l}\text { "Os professores docentes do Curso de ADM-EAD, lotados } \\
\text { em diferentes unidades da Universidade que possuem } \\
\text { interface com a área de Administração, visto que a maioria } \\
\text { deles também atuam no Programa de Pós-Graduação } \\
\text { em Administração, estarão envolvidos preferencialmente } \\
\text { nas atividades de produção do material pedagógico } \\
\text { (professores-autores) ...." } \\
\text { "... os candidatos [a tutoria] devem participar do processo } \\
\text { de formação que supõe a participação em um curso } \\
\text { sobre EAD, a participação de grupos de estudo sobre o } \\
\text { material didático do curso e questões relativas ao processo } \\
\text { de orientação". }\end{array}$ \\
\hline
\end{tabular}

EAD: educação a distância. 